\begin{abstract}
Introduction: The proportion of avoidable hospital deaths is challenging to estimate, but has great implications for quality improvement and health policy. Many studies and monitoring tools are based on selected high-risk populations, which may overestimate the proportion. Mandatory reporting systems, however, under-report. We hypothesize that a review of an unselected sample of hospital deaths will provide an estimate of avoidability in-between the estimates from these methods.
\end{abstract}

Methods: A retrospective case record review of an unselected population of 1,000 consecutive non-psychiatric hospital deaths in a Norwegian hospital trust was conducted. Reviewers evaluated to what degree each death could have been avoided, and identified problems in care. Results: We found 42 (4.2\%) of deaths to be at least probably avoidable (more than $50 \%$ chance of avoidability). Life expectancy was shortened by at least one year among 34 of the 42 patients with an avoidable death. Patients whose death was found to be avoidable were less functionally dependent compared with patients in the non-avoidable death group. The surgical department had the greatest proportion of such deaths. Very few of the avoidable deaths were reported to the hospital's report system.

Conclusions: Avoidable hospital deaths occur less frequently than estimated by the national monitoring tool, but much more frequently than reported through mandatory reporting systems. Regular reviews of an unselected sample of hospital deaths are likely to provide a better estimate of the proportion of avoidable deaths than the current methods. 


\section{INTRODUCTION}

There has been great interest in the topic of avoidable hospital deaths both politically and academically for many years.[1-3] Much of the debate has concerned the proportion of deaths that actually could have been avoided, ranging from a few percentages to over a half.[1,4-6] As patients differ in comorbidities, disease status and life expectancy, a main point of interest when assessing the quality of health care, is to what degree patients are exposed to potentially avoidable adverse events or problems with the healthcare that may increase morbidity or mortality. Retrospective case record review (RCRR), where experienced clinicians review the quality of health care given for individual patients, is a widely used method to assess the rate of avoidable deaths during hospital admissions.[5,7,8] The proportion of deaths during hospital care considered either to be probably ( $>50 \%$ chance of avoidability) or definitely avoidable as assessed by the RCRR-method has been reported to be $3-6 \%$ in different studies.[5,9-11] Other designs, such as the Global Trigger Tool (GTT) that are based on a selected high risk sample, tend to find a higher rate of possible avoidable hospital deaths.[1,6,12,13] The Norwegian National Safety Campaign, uses the latter design, and have reported possible avoidable deaths of around 4 - 16\%.[14,15] Mandatory report systems, on the other hand, seem to underestimate these deaths.[16]

The main aims of this study were to estimate the rate of and mechanisms behind avoidable deaths in an unselected group of consecutive non-psychiatric hospital deaths from a Norwegian health trust. Based on previous reports using the RCRR-method, we hypothesise that this approach will provide a more conservative estimate regarding the proportion of possible avoidable deaths as compared to methods based on high-risk samples, such as the GTT. 


\section{MATERIAL AND METHODS}

The [ANONYMISED] Hospital is a [ANONYMISED]-bed health trust located in [ANONYMISED], Norway. The health trust is affiliated with [ANONYMISED university], and consists of a larger tertiary care hospital and a smaller secondary care hospital. The health trust provides tertiary care for a population of about [ANONYMISED], and serves a local population of about [ANONYMISED] as their local health trust. In 2014, the health trust had [ANONYMISED] in-patient admissions of which approximately $62 \%$ were emergency admissions, which is representative of the national average.[17] Approximately 22\% of admitted in-patients had a residential address outside of the local health trust area.

\section{Patient inclusion}

The study was approved by the Regional Ethics Committee with reference number [ANONYMISED]. One thousand consecutive hospital deaths (including deaths in the emergency room) from December 2013 to February 2015 among patients above 16 years of age were included in the analysis. Patients dying in the psychiatric or obstetric wards were not included.

To evaluate representativeness of our study sample, we retrieved anonymised raw data from the Norwegian Cause of Death Registry. These data also included information on the national number of deaths reported to be due to medical errors.

\section{Chart review}

Five clinicians were recruited for the RCRR. There were two specialists in anaesthesiology and critical care, one general and vascular surgeon, one pulmonologist, and one specialist in internal medicine and cardiology. A forensic pathologist was consulted in some cases when autopsy reports needed clarification. The final distribution of the number of charts reviewed by the 
individual reviewers was uneven; the anaesthesiology/critical care, surgical and medical specialities contributed to $37 \%, 19 \%$, and $39 \%$ respectively. The reviewers were given full access to the electronic medical record system used at the health trust (Doculive, Siemens Nixdorf Information Systems, Oslo, Norway), including laboratory results and results from medical imaging. The medical record system is the same for all hospitals in the region referring patients to the tertiary care hospital. Thus, the reviewers were able to assess the care given at other hospitals before the index admission if this was relevant. Data collection was performed by a web-based case report form developed and administered by [ANONYMISED]. Our report forms were the same untranslated forms as used in a study by Hogan et al. that evaluated 2,400 hospital deaths in 24 English National Health Service hospitals, with some additional questions regarding level of treatment (Supplementary Material).[10]

\section{The review process}

The reviewers were experienced clinicians and administrators used to dealing with patient safety and quality improvement issues. They were introduced to the report form in a plenary reviewing session using five patient charts before each reviewer individually assessed the same ten randomly selected patients from the dataset. The reviewers then met to discuss each of the ten patient histories in order to ensure uniform practice when performing the RCRR. This procedure was repeated for another 40 randomly selected patients to optimise uniform evaluation. Each reviewer was then given a pre-specified number of patient charts to review, depending on how much time they could contribute. Reviewers were instructed to assess all aspects of patient care during the index admission and previous admissions to assess the quality of care given before death occurred. This included functional level, comorbidities according to the Charlson Comorbidity Index, diagnosis at admission, diagnosis at death, any episodes of health care falling below an acceptable standard, any decisions made to limit the level of care 
and any evidence of overtreatment during the course of the admission. The overall quality of the health care given was assessed. If the reviewers lacked competence in judging particular cases, they either consulted physicians in an appropriate sub-speciality or the case was taken back to the group. The reviewers made a judgement in each case as to whether or not the death could have been avoided on a six-point Likert Scale: 1 - Not avoidable; 2 - Slight evidence of avoidability; 3 - Possibly avoidable but not very likely, less than 50\%; 4 - Probably avoidable, more than 50\%; 5 - Strong evidence of avoidability; 6 - Definitely avoidable. In the main analyses, the three latter groups were jointly treated as at least probably (>50\%) avoidable.[5] The degree of avoidability was also scored on a continuous visual scale (0-100), and the reviewers were asked to judge how many days, months or years the patient's life was shortened. For all patients where a score of two or more was made on the Likert Scale, the patient history was discussed among all the reviewers in plenary and consensus was reached with respect to the degree of avoidability.

\section{Statistical analysis}

Data was extracted from the case report forms and analysed applying the software Matlab (The Mathworks, Natick, MA, USA) and the software SPSS (IBM Corp, Armonk, NY, USA). The software $\mathrm{R}$ version 3.3.2 and the software RStudio were used for statistical analysis (RCoreTeam, Vienna, Austria). Clinical data are presented as means with $95 \%$ confidence intervals $(95 \% \mathrm{CI})$, medians $\pm 25^{\text {th }}$ and $75^{\text {th }}$ percentiles $(25 \mathrm{p}, 75 \mathrm{p})$ or proportions. Differences between proportions were assessed applying the Chi-Square test or Fisher's test, as appropriate. Differences between non-normally distributed variables were assessed using the Wilcoxon's rank sum test. 


\section{RESULTS}

There were [ANONYMISED] patients admitted to the health trust during the study period, of whom 1,000 patients died and were included in the study. Baseline demographic data at the time of admission are presented in Table 1, and data on in-hospital clinical course are presented in Table 2. In the total study sample, the median age was 77 years (p25-p75, range 67-86), 55\% were male, and the median length of stay was 5 days (p25-p75, range 2-13), with similar demographics seen in the avoidable death group $(>50 \%)$. Twenty-five percent of patients died during the first 24 hours of admission. Based on data from the Norwegian Cause of Death Registry, we found that the age and sex distributions in our sample were comparable with all non-psychiatric hospital deaths in Norway in 2014 (Supplementary Table 1). When compared with all hospital deaths, our sample had a lower proportion of deaths due to neoplasms, and a higher proportion of deaths due to respiratory diseases. 
Table 1. Baseline characteristics

\begin{tabular}{|c|c|c|c|}
\hline & $\begin{array}{c}\text { Avoidable deaths }(>50 \%) \\
(n=42)\end{array}$ & $\begin{array}{c}\text { Non-avoidable deaths } \\
(\mathrm{n}=958)\end{array}$ & \\
\hline & \multicolumn{2}{|c|}{$\mathrm{n}(\%)$} & p-value \\
\hline Male sex & $23(55)$ & $527(55)$ & 0.97 \\
\hline Emergency admission & $29(69)$ & $882(92)$ & $<0.01$ \\
\hline \multicolumn{4}{|l|}{ Admitting speciality } \\
\hline Medical & $20(48)$ & $629(66)$ & 0.02 \\
\hline Surgical & $22(51)$ & $176(18)$ & $<0.01$ \\
\hline Oncological & $0(0)$ & $148(15)$ & $<0.01$ \\
\hline Neurological & $0(0)$ & $5(1)$ & 1.00 \\
\hline \multicolumn{4}{|l|}{ Admitted from } \\
\hline Home & $40(95)$ & $852(89)$ & 0.19 \\
\hline Institution & $0(0)$ & $48(5)$ & 0.25 \\
\hline Other & $2(5)$ & $58(6)$ & 1.00 \\
\hline \multicolumn{4}{|l|}{$\begin{array}{l}\text { Degree of dependency before index } \\
\text { admission }\end{array}$} \\
\hline Fully independent & $25(60)$ & $249(26)$ & $<0.01$ \\
\hline Mild impairment & $10(24)$ & $289(30)$ & 0.37 \\
\hline Dependent on others & $6(14)$ & $389(41)$ & $<0.01$ \\
\hline \multirow[t]{2}{*}{ Unable to determine } & $1(2)$ & $24(3)$ & 1.00 \\
\hline & \multicolumn{2}{|c|}{ Median (p25-p75) } & p-value \\
\hline Age (years) & $78(70-86)$ & $77(67-86)$ & 0.53 \\
\hline Length of admission (days) & $5(2-14)$ & $5(2-13)$ & 0.97 \\
\hline Charlson Comorbidity Index (points) & $2(1-3)$ & $3(1-6)$ & 0.02 \\
\hline
\end{tabular}


Table 2. Patient care and outcome

\begin{tabular}{|c|c|c|c|}
\hline & $\begin{array}{c}\text { Avoidable deaths }(>50 \%) \\
(n=42)\end{array}$ & $\begin{array}{c}\text { Non-avoidable deaths } \\
(\mathrm{n}=958)\end{array}$ & \\
\hline & & & p-value \\
\hline \multicolumn{4}{|l|}{ Main diagnosis at time of death } \\
\hline Infectious and parasitic diseases & $5(12)$ & $53(6)$ & 0.08 \\
\hline Neoplasms & $8(19)$ & $165(17)$ & 0.76 \\
\hline Diseases of the nervous system & $0(0)$ & $13(1)$ & 1.00 \\
\hline Diseases of the circulatory system & $10(24)$ & $291(30)$ & 0.36 \\
\hline Diseases of the respiratory system & $5(12)$ & $177(18)$ & 0.41 \\
\hline Diseases of the digestive system & $4(9)$ & $48(5)$ & 0.27 \\
\hline Diseases of the genitourinary system & $3(7)$ & $27(3)$ & 0.13 \\
\hline $\begin{array}{l}\text { Injury, poisoning and certain other } \\
\text { consequences of external causes }\end{array}$ & $7(16)$ & $52(5)$ & $<0.01$ \\
\hline Miscellaneous & $2(5)$ & $133(14)$ & 0.11 \\
\hline Admitted to ICU or HDU & $27(64)$ & $443(46)$ & 0.02 \\
\hline $\begin{array}{l}\text { Episode of confusion at any point } \\
\text { during hospital stay }\end{array}$ & $13(31)$ & 347 (36) & 0.48 \\
\hline $\begin{array}{l}\text { Received surgical treatment during } \\
\text { admission }\end{array}$ & $22(52)$ & $120(12)$ & $<0.01$ \\
\hline \multicolumn{4}{|l|}{ Overall quality of care } \\
\hline Excellent & $2(5)$ & $133(14)$ & 0.09 \\
\hline Good & $13(31)$ & $752(79)$ & $<0.01$ \\
\hline Adequate & $6(14)$ & $53(5)$ & 0.02 \\
\hline Poor & $21(50)$ & $13(2)$ & $<0.01$ \\
\hline Very poor & $0(0)$ & $0(0)$ & 1.00 \\
\hline Unable to determine & $0(0)$ & $7(8)$ & 1.00 \\
\hline
\end{tabular}

HDU, high dependency unit; ICU, intensive care unit. 
The reviewers found that for $42(4.2 \%)$ patients the death was either probably or definitely avoidable (Likert scale 4-6; avoidability >50\%; Table 3), and that for additional 25 (2.5\%) patients there was slight or possible evidence that death could have been avoided (Likert scale 2 or 3; avoidability $<50 \%$ ). The proportion of deaths assessed by the individual reviewers as probably avoidable ranged from $0.0 \%$ to $9.0 \%$ (median $4.6 \%$; Supplementary Table 2). For 22 of the patients, the reviewers judged on a continuous visual scale that the probability of an avoidable death was $80 \%$ or more. Life expectancy was shortened by at least one year among 34 of the 42 patients $(81.0 \%)$ with an avoidable death. The place where death could most commonly be avoided was during invasive procedure (35\%). The different types of problems found in the delivery of health care, including any contributory factors, are presented in Table 4. Data from the Norwegian Cause of Death Registry showed that $14(0.1 \%)$ of 12,578 inhospital deaths were reported as due to medical error in Norway in 2014, and an additional 378 $(3.0 \%)$ were reported as sudden and unexpected, or special circumstances with unknown cause. These numbers were similar in 2012-2016. Only three reports regarding the 42 avoidable deaths were found in the hospital's mandatory report system. 
Table 3. Avoidability

Avoidable deaths (>50\%)

$(n=42)$

$\mathrm{n}(\%)$

Degree of avoidability

Likert 4; Probably avoidable, more than $50-50$ but close call

$21(50)$

Likert 5; Strong evidence avoidability

$18(43)$

Likert 6; Definitely avoidable

Place where problem in health care could have been avoided

Primary care / ambulance

In prior admission

In initial assessment unit

During invasive procedure

During postoperative care

$3(7)$

During HDU/ICU care

Ward

The time life was shortened by if death had been avoided

$<3$ months

3 months -1 year

$1-5$ years

5 years or more

Degree of avoidability on visual scale from 0-100

Median (p25-p75)

HDU, high dependency unit; ICU, intensive care unit. $80(60-90)$ 
Table 4. Contributory factors to avoidable patient death

\begin{tabular}{|c|c|}
\hline & $\begin{array}{l}\text { Avoidable deaths }(>50 \%) \\
(n=42)\end{array}$ \\
\hline & $\mathrm{n}(\%)$ \\
\hline \multicolumn{2}{|l|}{ Type of problem in health care } \\
\hline Problem in assessment, investigation or diagnosis. & $7(17)$ \\
\hline $\begin{array}{l}\text { Problem with medication/intravenous fluids/electrolytes/oxygen } \\
\text { (other than anaesthetic). }\end{array}$ & $7(17)$ \\
\hline Problem related to treatment and management plan. & $7(17)$ \\
\hline Problem with infection control. & $1(2)$ \\
\hline Problem related to operation/invasive procedure. & $16(38)$ \\
\hline Problem in clinical monitoring. & $1(2)$ \\
\hline Problem in resuscitation following a cardiac or respiratory arrest. & $0(0)$ \\
\hline Any other problem not fitting categories above. & $1(2)$ \\
\hline Not specified. & $2(5)$ \\
\hline \multicolumn{2}{|l|}{ Apparent contributory factors to problem in healthcare } \\
\hline Not possible to identify any clear contributory factors. & $14(33)$ \\
\hline Patient related factors (e.g. non-compliance). & $4(10)$ \\
\hline $\begin{array}{l}\text { Individual staff factors (e.g. lack of insight into own competency } \\
\text { levels, failure to seek help, exhausted, etc.). }\end{array}$ & $2(5)$ \\
\hline $\begin{array}{l}\text { Training, education and supervision factors (e.g. lack of } \\
\text { skills/experience, lack of awareness of risks, inadequate } \\
\text { supervision). }\end{array}$ & $12(29)$ \\
\hline $\begin{array}{l}\text { Task design, guideline and protocol factors (e.g. misleading } \\
\text { equipment design, outdated local protocol, missing or } \\
\text { contradictory guidance). }\end{array}$ & $4(10)$ \\
\hline $\begin{array}{l}\text { Teamwork, leadership and communication factors (e.g. inadequate } \\
\text { handover, inadequate inter-professional challenge, weak } \\
\text { leadership etc.). }\end{array}$ & $2(5)$ \\
\hline $\begin{array}{l}\text { Local work environment factors (e.g. noise, distractions, } \\
\text { inadequate staffing, resources, missing equipment). }\end{array}$ & $0(0)$ \\
\hline $\begin{array}{l}\text { Organisation-wide factors (e.g. overall bed capacity, design of IT } \\
\text { systems etc.). }\end{array}$ & $1(2)$ \\
\hline Other type of contributory factor. & $1(2)$ \\
\hline Several factors. & $2(5)$ \\
\hline
\end{tabular}

A decision on the level of treatment to provide for the patients was decided after the index admission for the majority of patients $(62 \%)$, whereas for a minority $(5.2 \%)$ this had been decided prior to the index admission. A do-not-resuscitate decision was the most common limitation $(50.1 \%)$, followed by limitation of invasive respiratory support (16.3\%), limitation 
of any respiratory support (11.1\%), limitation of other life-prolonging efforts $(7.5 \%)$ and limitation of any surgery (3.6\%). Eleven patients $(1.1 \%)$ were exposed to an intrusive or invasive procedure that were considered not to be in their best interest as part of end-of-life care. Of these, five patients were given inappropriate respiratory support, four patients received inappropriate cardiopulmonary resuscitation and three patients were subject to a surgical procedure that was not indicated. 


\section{DISCUSSION}

\section{Main findings}

In an unselected population of consecutive non-psychiatric hospital deaths, we found that $4.2 \%$ of the 1,000 evaluated deaths were judged to be at least "probably avoidable". By including the "possibly avoidable" deaths the proportion would increase to $5.1 \%$, while a stricter definition of at least "strong evidence" of avoidability would leave $2.2 \%$ avoidable deaths. Those with an avoidable death were of comparable age and sex to the non-avoidable death group, but were less functionally dependent, and were more likely to be admitted to a surgical unit. In addition, the care given to those with a possibly avoidable death was of poorer quality. Death could most frequently have been avoided during an invasive procedure. Based on age, sex and diagnosis at time of death, our sample was representative of all in-hospital deaths in Norway in 2014, albeit with a lower percentage of deaths due to neoplasms. A crude estimate based on our findings implies approximately 550 avoidable non-psychiatric hospital deaths in Norway in 2014.

\section{Comparison with literature}

Many studies set in hospitals have reported similar results to ours, with avoidable deaths ranging from $3 \%$ to $6 \%$.[3-5,10] Flaatten et al. published a study in 2016, where they evaluated approximately the same number of patients in a hospital setting in another part of Norway.[11] They judged $2.9 \%(n=34)$ of deaths to be at least probably avoidable $(>50 \%)$. The difference compared to our finding may be partly due to random error, but may also be explained by differing methods (e.g. Flaatten et al. only evaluated deaths due to unexpected, unnatural causes).

Other studies have reported a much higher proportion of avoidable deaths. Before launching the Norwegian National Safety Campaign ("In safe hands") in 2011, the Norwegian Health Directory estimated that $0,66 \%$ of patients admitted to Norwegian hospitals died due to 
adverse events, approximately 4,722 patients a year.[15] Half of these adverse events, including deaths, were considered to be potentially avoidable.[18,19] Based on 14,625 deaths in nonpsychiatric hospitals in 2010 , this would equate to approximately $16 \%$ of deaths being avoidable. This estimate was an extrapolation based on multiple studies, including a Swedish study of adverse events in hospitals which found that $70 \%$ were avoidable, and that five of the ten adverse events that led to death were avoidable.[20] Studies from Danish and Australian hospitals have reported similarly high proportions of avoidable deaths.[6,12] These studies base their methods on the much publicised Harvard Medical Practice Study (HMPS) from 1991, which reported that half of all deaths from adverse events were caused by negligence.[1] However, the HMPS study was designed to measure the prevalence of harm from medical care and not to estimate the number of deaths due to medical error, and relatively few deaths were examined. Those that were, had already been screened as positive for an "unexpected death" in the first stage of the process. This is in contrast to our method where we estimate avoidability among all deaths.

The Global Trigger Tool (GTT) method is a systematisation of the HMPS process, where a small, random number of hospital admissions are screened for predefined triggers. This is the method used by the Norwegian National Safety Campaign.[14] In 2014, out of 569,180 hospital admissions, 8,804 were reviewed by 36 GTT teams. Of these admissions, $0.25 \%$ were found to have an adverse event that led to death, which equals approximately 22 deaths, or on average 0.6 deaths per GTT team. The Norwegian National Safety Campaign often cite that half of all adverse events are avoidable, in which case their results indicate that there were $5.7 \%$ potentially avoidable hospital deaths out of 12,578 in 2014.

An evident problem with the GTT approach is the small number of patients evaluated. This may partly explain the 4-fold decrease in the proportion of adverse events leading to death between 2010 and 2015 (0.65\% and $0.17 \%$, respectively). As with the HMPS the deaths 
reviewed by this method are pre-selected. Finally, the GTT approach is not designed to evaluate the causal relationship between adverse events and harm, including death. However, these extrapolations are commonly made.[18,19] We argue, as others have, that in order to evaluate the mechanisms behind avoidable hospital deaths, one should take an unselected number of deaths, using the RCRR method.[10,11]

Only $0.1 \%$ of hospital deaths were reported to be due to medical error in the Norwegian Cause of Death Registry. Cause of death and suspicion of unnatural death are reported to the Norwegian Institute of Health by the doctor who examines the dead body, although the reliability of the reports is sub-optimal.[21] Additionally, it is mandatory to report any considerable patient harm to the Norwegian Directorate of Health.[22] Of the 42 patients in our sample with $>50 \%$ avoidability, only three were reported to this mandatory reporting system. There is evidently considerable underreporting of avoidable deaths to both the Norwegian Cause of Death Registry and the Norwegian Directorate of Health.

Furthermore, we found that avoidable deaths were less likely to occur among dependent patients, and patients with a high comorbidity score. This has been described in other reports,[5] and is surprising given that other studies have found more adverse events and avoidable deaths among elderly and those with disability, citing complexity as a potential reason.[4,6,23] It could be hypothesised that more attention is paid to the frail, leaving less room for error. A more likely explanation is that it's easier to judge an event as non-avoidable when the medical history of a patient is complex. We also found that a higher proportion of avoidable deaths occurred amongst surgical patients. This has also been observed in previous studies.[4,5,11] Some of this difference may be explained by the fact that medical errors, both of omission and commission, are more easily discerned in surgery than elsewhere. Additionally, one may speculate that patients scheduled for surgery are generally in better health than those on a medical ward, leading reviewers to judge the surgery (and not other factors) as causally related to death. 
Nevertheless, it is also possible that there are, in fact, more errors made during surgical treatment compared to medical treatment. $[5,24]$ One effort to improve safety of the surgical patient was initiated in 2008 by the World Health Organization in form of a 19-item checklist, which has proven to be effective in a number of countries including Norway.[25,26]

We identified problems during invasive procedures as the most common cause of avoidable deaths, followed by those that occurred during initial assessment and those prior to admission. These findings differ from a similar study by Hogan et al. where most errors happened during general ward care.[5] However, their population was somewhat older than ours, and while our study population was roughly equally distributed between medical and surgical wards, three quarters of their population were admitted to a medical ward. As would be expected, overall quality of care was found to be worse among those with avoidable deaths compared with the rest, although no episode of care was judged as "very poor". This is in accordance with the study by Hogan et al.[5] Of the identified factors that contributed to the avoidable deaths, those related to training, education and supervision were the most common.

\section{Strengths and limitations}

To our knowledge, this is the largest study in a Nordic country evaluating the mechanisms behind avoidable deaths in an unselected sample of non-psychiatric hospital deaths. Our study sample was representative of all non-psychiatric hospital deaths, based on data from the Norwegian Cause of Death Registry. However, there are some important limitations.

One limitation is that we only evaluated one hospital trust. Although our study population was comparable to all non-psychiatric hospital deaths in the study period, we do not know whether the proportion or causes of avoidable deaths that we report are generalisable to other hospitals in Norway. 
The case review process is a qualitative one. While increasing the number of subjects under review may limit random error, it will not remove systematic error. One source of bias, hindsight bias, is likely to affect all RCRR;[3,27] Knowledge of the outcome permits "second guessing" and facilitates overestimation of the rate of medical errors.[28] This is potentiated when causality between the error at hand and the outcome is difficult to disentangle. Answering questions such as "what would have happened with the patient had the error not occurred?" is challenging, and reflects both the complexity of modern medicine, and the difficulty of assessing potential error in patient care based on incomplete information found in medical records. On the other hand, it is also known that reviewers tend to overestimate the occurrence of rare events, which could also be the case in the present study.[9,29] These issues compromise inter-rater reliability, another well-known limitation of RCRR.[3,9] In fact, some authors have argued that close to all active-care deaths will be judged as avoidable given enough observers.[9] We used only one reviewer per case initially. Where there was uncertainty around judgements, the case was subsequently discussed in a plenary session. This limitation could possibly affect our overall result in either direction. We implemented a number of steps to increase the reliability of the reviews (standardised review form, training, whole group review of 55 records, building consensus around difficult cases), but we did not formally test this measure and are unable to compare our performance with other studies.

The proportion of avoidable deaths may also be underestimated. For instance, medical records can to be less descriptive when errors are made, which may inhibit detection.[30] Furthermore, the fact that our study reviewers were clinicians at the same hospital trust from which the study population was drawn may have contributed to an underestimation of potential avoidability. 


\title{
Conclusions and implications
}

In conclusion, we found that $4.2 \%$ of deaths in our representative sample of 1,000 hospital deaths were at least probably avoidable, which is consistent with other studies using the RCRR approach.[3-5,10] Given that the GTT approach applied by Norwegian National Safety Campaign tends to classify too many deaths as potentially avoidable, and both the Norwegian Cause of Death Registry and the Norwegian Directorate of Health mandatory reporting system provide far too conservative estimates, we argue that the proportion of avoidable deaths is best estimated by evaluating an unselected sample of all hospital deaths. Avoidable deaths represent an important marker of hospital quality of care, and reductions can be achieved by improving training, education and supervision. As patient safety is one of the priorities of the Norwegian government to improve hospital quality of care,[31] a national focus on detecting such deaths through RCRR would be one way of achieving this goal.

\section{ACKNOWLEDGEMENTS}

\author{
[ANONYMISED]
}

\section{COMPETING INTERESTS}

The authors have no conflicts of interests to report.

\section{FUNDING}

The funding source was not involved in the design of the study, statistical analyses or interpretation of the results. The researchers were independent from the funding source. 


\section{References}

1 Brennan TA, Leape LL, Laird NM, et al. Incidence of Adverse Events and Negligence in Hospitalized Patients. N Engl J Med 1991;324:370-6.

doi:10.1056/NEJM199102073240604

2 Brennan TA. The Institute of Medicine Report on Medical Errors - Could It Do Harm? N Engl J Med 2000;342:1123-5. doi:10.1056/NEJM200004133421510

3 Hogan H. The problem with preventable deaths. BMJ Qual Saf 2016;25:320-3. doi:10.1136/bmjqs-2015-004983

4 Zegers M, de Bruijne MC, Wagner C, et al. Adverse events and potentially preventable deaths in Dutch hospitals: results of a retrospective patient record review study. Qual Saf Heal Care 2009;18:297-302. doi:10.1136/qshc.2007.025924

5 Hogan H, Healey F, Neale G, et al. Preventable deaths due to problems in care in English acute hospitals: a retrospective case record review study. BMJ Qual Saf 2012;21:737-45. doi:10.1136/bmjqs-2011-001159

6 Wilson RM, Runciman WB, Gibberd RW, et al. The Quality in Australian Health Care Study. Med J Aust 1995;163:458-71.

7 Michel P, Quenon JL, de Sarasqueta AM, et al. Comparison of three methods for estimating rates of adverse events and rates of preventable adverse events in acute care hospitals. BMJ 2004;328:199. doi:10.1136/bmj.328.7433.199

8 Shojania KG, DIxon-Woods M. Estimating deaths due to medical error: The ongoing controversy and why it matters. BMJ Qual Saf 2017;26:423-8. doi:10.1136/bmjqs2016-006144

9 Hayward RA, Hofer TP. Estimating hospital deaths due to medical errors: preventability is in the eye of the reviewer. Jama 2001;286:415-20. doi:10.1001/jama.286.4.415 
10 Hogan H, Zipfel R, Neuburger J, et al. Avoidability of hospital deaths and association with hospital-wide mortality ratios: retrospective case record review and regression analysis. BMJ 2015;351:h3239. doi:10.1136/bmj.h3239

11 Flaatten H, Brattebø G, Alme B, et al. Adverse events and in-hospital mortality: an analysis of all deaths in a Norwegian health trust during 2011. BMC Health Serv Res 2017;17:465. doi:10.1186/s12913-017-2417-7

12 Schiøler T, Lipczak H, Pedersen BL, et al. [Incidence of adverse events in hospitals. A retrospective study of medical records]. Ugeskr Laeger 2001;163:5370-8.

13 Makary MA, Daniel M. Medical error-the third leading cause of death in the US. BMJ 2016;353:1-5. doi:10.1136/bmj.i2139

14 Helsedirektoratet. Pasientskader i Norge 2016 målt med Global Trigger Tool. 2017.

15 Helsedirektoratet. Kort om resultatene fra kartlegging av pasientskader fra 2010. 2011.

16 Smeby SS, Johnsen R, Marhaug G. Documentation and disclosure of adverse events that led to compensated patient injury in a Norwegian university hospital. Int J Qual Heal Care 2015;27:486-91. doi:10.1093/intqhc/mzv084

17 Statistisk sentralbyrå. Pasienter på sykehus, 2013. 2014.

18 Helsedirektoratet. Hvor mange skades i norske sykehus? 2012.

19 Saltbones I, Gjerdin ML, Sundbye B. Rapport : - 4500 dødsfall skyldes sykehusskader. VG. 2011.

20 Soop M, Fryksmark U, Koster M, et al. The incidence of adverse events in Swedish hospitals: a retrospective medical record review study. Int J Qual Heal Care 2009;21:285-91. doi:10.1093/intqhe/mzp025

21 Pederson A, Ellingson C. Data quality in the Causes of Death Registry - Tidsskrift for Den norske legeforening. Tidsskr Nor Legeforen 2015;135:768-70.

22 Helsedirektoratet. Veileder til spesialisthelsetjenesteloven § 3-3 - Meldeplikt til 
Helsedirektoratet. Oslo: 2016.

23 Thomas EJ, Brennan TA. Incidence and types of preventable adverse events in elderly patients : population based review of medical records. BMJ 2000;320:741-4.

24 Giraldo P, Sato L, Sala M, et al. A retrospective review of medical errors adjudicated in court between 2002 and 2012 in Spain. Int J Qual Heal Care 2016;28:33-9. doi:10.1093/intqhe/mzv089

25 Haynes AB, Weiser TG, Berry WR, et al. A surgical safety checklist to reduce morbidity and mortality in a global population. N Engl J Med 2009;360:491-9. doi:10.1056/NEJMsa0810119

26 Haugen AS, Wæhle HV, Almeland SK, et al. Causal Analysis of World Health Organization's Surgical Safety Checklist Implementation Quality and Impact on Care Processes and Patient Outcomes. Ann Surg 2017;:1.

doi:10.1097/SLA.0000000000002584

27 Lilford R, Edwards A, Girling A, et al. Inter-rater reliability of case-note audit: A systematic review. J Heal Serv Res Policy 2007;12:173-80. doi:10.1258/135581907781543012

28 Caplan RA, Posner KL, Cheney FW. Effect of outcome on physician judgments of appropriateness of care. JAMA 1991;265:1957-60.

29 Kobewka DM, van Walraven C, Taljaard M, et al. The prevalence of potentially preventable deaths in an acute care hospital: A retrospective cohort. Medicine (Baltimore) 2017;96:e6162. doi:10.1097/MD.0000000000006162

30 Weingart SN, Wilson RM, Gibberd RW, et al. Epidemiology of medical error. BMJ 2000;320:774-7. doi:10.1136/ewjm.172.6.390

31 Helse- og omsorgsdepartementet. Meld. St. 11 (2015-2016). Nasjonal helse-og sykehusplan (2016-2019). 2016. 
